\title{
Outcomes of cervical lymph node recurrence in patients with esophageal squamous cell carcinoma after esophagectomy with 2 -field lymph node dissection
}

Deok Heon Lee, MD, Hyeong Ryul Kim, MD, PhD, Dong Kwan Kim, MD, PhD, Seung-Il Park, MD, $\mathrm{PhD}$, and Yong-Hee Kim, MD, $\mathrm{PhD}$

Objective: The purpose of this study is to investigate the clinical characteristics, prognosis, and risk factors of patients in whom cervical lymph node cancer recurred after esophageal cancer surgery with 2-field lymph node dissection.

Methods: Between 2000 and 2010, 471 consecutive patients who had undergone esophagectomy with 2-field lymph node dissection for esophageal squamous cell carcinoma were enrolled in this study.

Results: Recurrence was seen in 96 patients. Isolated cervical lymph node recurrence (group A) developed in 21 patients, locoregional recurrence only and without cervical lymph node recurrence (group B) in 29, and distant recurrence with or without locoregional recurrence (group C) in 46 patients. The median times to recurrence after surgery in groups $\mathrm{A}, \mathrm{B}$, and $\mathrm{C}$ were 20,16 , and 12 months, respectively $(P=.634)$. 2 - and 5-year rates of isolated cervical lymph node recurrence were $4.1 \%$ and $5.6 \%$, respectively. The median survival times from diagnosis of recurrence were 13, 7, and 5 months in groups $\mathrm{A}, \mathrm{B}$, and $\mathrm{C}$, respectively. The difference in survival between groups $\mathrm{A}$ and $\mathrm{C}$ was statistically significant $(P=.030)$. Upper thoracic esophageal cancer and positive recurrent laryngeal node at the time of initial surgery were independent risk factors for cervical recurrence-free survival as determined by univariate and multivariate analysis.

Conclusions: This study shows that 2-field lymph node dissection can be performed with an acceptable rate of cervical lymph node recurrence. Patients with isolated cervical lymph node recurrence demonstrated longer survival from diagnosis of recurrence than patients with other sites of recurrence. (J Thorac Cardiovasc Surg 2013;146:365-71)

The prognosis of patients with esophageal carcinoma has been historically dismal and the operative mortality for esophagectomy was relatively high at approximately $30 \%$ before the 1980s. ${ }^{1}$ More recently, it has been reported that operative mortality has decreased to less than $5 \%$ in highvolume medical centers. ${ }^{2}$ Despite the improvements in the various treatment methods, ${ }^{3}$ long-term patient survival is still unsatisfactory inasmuch as recurrent disease develops in large numbers of patients after curative esophagectomy. Lymph node recurrence in the cervical, mediastinal, and abdominal regions is widely recognized as one of the most important prognostic factors. ${ }^{4-6}$ However, a cervical lymph node recurrence has the chance for a complete cure with the use of appropriate treatment modalities compared

\footnotetext{
From the Division of Thoracic Surgery, Department of Thoracic and Cardiovascular Surgery, Asan Medical Center, University of Ulsan College of Medicine, Seoul, Republic of Korea.

Disclosures: Authors have nothing to disclose with regard to commercial support.

Received for publication July 4, 2012; revisions received Jan 14, 2013; accepted for publication Jan 28, 2013; available ahead of print Feb 19, 2013.

Address for reprints: Yong-Hee Kim, MD, PhD, Division of Thoracic Surgery, Department of Thoracic and Cardiovascular Surgery, Asan Medical Center, University of Ulsan College of Medicine, 88 Olympic-ro 43-Gil, Songpa-Gu, Seoul, 138-736, Republic of Korea (E-mail: kimyh67md@hotmail.com). $0022-5223 / \$ 36.00$

Copyright (C) 2013 by The American Association for Thoracic Surgery http://dx.doi.org/10.1016/j.jtcvs.2013.01.043
}

with recurrence at other sites. ${ }^{7}$ Some surgeons have used extended esophagectomy with 3-field lymph node dissection to improve long-term surgical outcomes. ${ }^{8,9}$ On the other hand, other surgeons have suggested that extended nodal dissection has little or no survival benefit and, in fact, a relative higher morbidity. ${ }^{10,11}$ Therefore, the role of the optimal extent of lymph node dissection during esophagectomy has not yet been established.

Our institution has mainly performed esophagectomy with 2-field (mediastinal and abdominal lymph node) lymph node dissection; thus cervical lymph node dissection was not performed in all patients of this study. The objectives of the present study are to investigate the clinical characteristics and the prognosis of patients in whom cervical lymph node cancer recurred after curative esophagectomy with 2-field lymph node dissection for esophageal squamous cell carcinoma.

\section{PATIENTS AND METHODS}

The Institutional Review Board of Asan Medical Center, University of Ulsan College of Medicine, in the Republic of Korea, approved this study.

\section{Patient Population}

Retrospective analysis was performed using a prospectively collected database of patients who underwent esophageal resection and reconstruction for the period from January 2000 to December 2010 at Asan Medical Center, Seoul, Korea. Six hundred sixty-six patients with esophageal 


\section{Abbreviations and Acronyms \\ AJCC $=$ American Joint Committee on Cancer \\ $\mathrm{CI}=$ confidence interval \\ $\mathrm{CT}=$ computed tomography}

cancer underwent surgical resection. This study included any patients (1) who had a histologic diagnosis of esophageal squamous cell carcinoma, (2) who underwent esophagectomy with R0 resection, and (3) who underwent 2 -field lymph node dissection. It excluded any patients who had hypopharyngeal cancer or cervical esophageal cancer, which are located above $20 \mathrm{~cm}$ from the upper incisors by endoscopic measurements. Four hundred seventy-one consecutive patients who met these inclusion and exclusion criteria were enrolled in the present study.

Our study included $439(93.2 \%)$ men and $32(6.8 \%)$ women with a mean age of 62.6 years (range, 38-94 years). The median follow-up period was 35 months (range, 1-132) months. There were 12 (2.5\%) deaths within 30 days after surgery. The causes of death were postoperative pneumonia with acute respiratory failure in 9 patients, empyema with septic shock in 1, acute renal failure with multiorgan failure in 1 , and deep vein thrombosis with hepatic failure in 1 . Vocal cord palsy occurred in $36(7.6 \%)$ patients: the left vocal cord in 27 ; the right vocal cord in 6 , and bilaterally in 3 .

\section{Surgical Procedures}

The operations were performed by 2 surgeons. The Ivor Lewis operation (median laparotomy and right transthoracic esophagectomy with reconstruction) and the McKeown operation (right thoracotomy, median laparotomy, and left cervical esophagectomy with reconstruction) are the usual procedures used for esophagectomy at our institution. Cervical esophagectomy with reconstruction is usually performed when the proximal tumor margin is located above $25 \mathrm{~cm}$ from upper incisor, as determined by esophagogastroscopic evaluation. A method of anastomosis, including manual anastomosis, circular stapler anastomosis, or semimechanical anastomosis with a linear stapler, was decided according to the surgeon's preference or the patient's characteristics. The definition of our 2-field lymph node dissection was resection of the mediastinal and abdominal lymph node stations. A meticulous dissection of upper, middle, and lower paraesophageal, subcarinal, upper and lower paratracheal, and a right and left pulmonary hilar lymph node was followed by thoracic esophageal resection. The right recurrent laryngeal nerve chain was fully dissected during mediastinal lymph node dissection, but the left recurrent laryngeal nerve chain was not routinely dissected. The abdominal lymph nodes were dissected, including paracardiac nodes, nodes along the perigastric lesser curvature, left gastric artery nodes, celiac axis nodes, and common hepatic artery nodes, through median laparotomy.

\section{TNM Staging, Neoadjuvant Therapy, and Follow-up}

In our study, the clinical staging was based on the sixth American Joint Committee on Cancer (AJCC) TNM classification, ${ }^{12}$ because it was nearly impossible to determine the clinical stage, according to the seventh AJCC TNM classification, without pathologic confirmation of lymph nodes during the retrospective review of preoperative evaluations. However, the pathologic staging was based on the revised seventh AJCC TNM classification. ${ }^{13}$ One hundred ninety-four $(41.2 \%)$ patients of 471 study population received protocol-based neoadjuvant chemoradiation before curative esophagectomy. The protocol-based treatment plan for patients with esophageal cancer at our institution, which has been followed since 1993, has been described previously ${ }^{14-16}$ and meant that the incidence of neoadjuvant therapy was higher than that seen in other studies. Neoadjuvant therapy was administered (1) when the patients had a greater than $\mathrm{T} 2$ or $\mathrm{N} 1$ stage in preoperative clinical evaluations, (2) when the patient's age was less than 75 years, (3) when the patient was otherwise medically well without significant other diseases, and (4) when the patient consented to neoadjuvant treatment. Surgery was performed within 4 to 8 weeks from the end of the neoadjuvant treatment. We performed immediate operation when patients had clinical T1 and N0 stage or when patients could not receive neoadjuvant treatment. Therefore, the pathologic staging after neoadjuvant therapy and followed by esophagectomy may not reflect the true extent of disease seen before treatment. In other words, there may be strict differences between pT1 and ypT1 despite the same anatomic extent of disease at the time of each respective pathologic examination. However, in this study the pathologic staging was described without the distinction of receiving or not receiving neoadjuvant therapy.

Postoperative follow-up was conducted at the attending surgeons', medical, and radiation oncologists' outpatient clinics. All patients were followed up at 3-month intervals for the first year and at 6-month intervals thereafter. Simple chest radiography and chest and upper abdominal computed tomography (CT) were performed at every follow-up period, and an esophagogastroscopy and positron emission tomography CT were performed annually or more frequently if any recurrence was suspected. More specific investigations, such as whole-body bone scintigraphy, brain $\mathrm{CT}$, or magnetic resonance imaging, were sometimes performed on the basis of a patient's suggestive symptoms, physical examination, or biochemical markers.

\section{Definition of Recurrence}

Locoregional recurrence was defined as a recurrence that developed at the site of previous esophagectomy or as lymph nodes in the cervical, mediastinal, or upper abdominal area. Distant recurrence was defined as that occurring in a solid organ through hematogenous spread. Combined recurrence was defined as both locoregional and distant recurrence found within 30 days. Diagnosis of recurrent disease was based on histologic evaluation or definite radiologic findings. We divided the patients with recurrence into 3 groups to investigate the pattern of cervical lymph node recurrence and survival: group A, recurrence was detected only in the cervical lymph nodes; group B, recurrence occurred in a locoregional area and without cervical lymph node recurrence; and group $\mathrm{C}$, distant recurrence was observed with or without locoregional recurrence.

We then compared the times to recurrence after the surgery and survival times after the recurrence in the 3 groups. The risk factors associated with recurrence-free survival of patients with cervical recurrence (group A) and the survival times after the treatments for the cervical recurrence (group A) were also evaluated.

\section{Statistical Analysis}

Statistical evaluation was performed using the Statistical Package for the Social Sciences (SPSS) program version 19.0 for Windows (SPSS, Inc, Chicago, Ill). Continuous variables were analyzed using the Student $t$ test (Mann-Whitney $U$ test) or 1-way analysis of variance (KruskalWallis), and discrete variables were analyzed using the Pearson $\chi^{2}$ test (Fisher's exact test). Survival after recurrences was defined as the duration from recurrence to a patient's death from any cause or last follow-up. Risk factors associated with recurrence-free survival of patient with cervical recurrence (group A) were evaluated by univariate analysis considering age, gender, neoadjuvant therapy, tumor location, clinical $\mathrm{T}$ and $\mathrm{N}$ stage, pathologic $\mathrm{T}$ and $\mathrm{N}$ stage, histologic grade of tumor, and involvement of recurrent laryngeal lymph nodes. Recurrence rates and survivals were derived using the Kaplan-Meier method, and the differences between subgroups were assessed using the log-rank test. The Cox regression model was used for multivariate analysis to determine independent risk factors.

\section{RESULTS}

The demographic, operative, distribution of recurrences, clinical, and pathologic data of our study population are 
TABLE 1. Demographic and operative data of our study population

\begin{tabular}{|c|c|c|c|c|c|}
\hline Variable & All patients $(n=471)$ & Group A $(n=21)$ & Group B $(\mathbf{n}=29)$ & Group C $(n=46)$ & $P$ value \\
\hline Age, y (mean \pm SD) & $62.6 \pm 7.8$ & $61.2 \pm 8.2$ & $63.5 \pm 5.7$ & $64.1 \pm 7.3$ & .382 \\
\hline Gender $(\%)$ & & & & & .220 \\
\hline Male & $439(93.2)$ & $20(95.2)$ & $27(93.1)$ & $46(100)$ & \\
\hline Tumor location (\%) & & & & & .099 \\
\hline Upper thoracic & $36(7.6)$ & $5(23.8)$ & $4(13.8)$ & $2(4.3)$ & \\
\hline Middle thoracic & $258(54.8)$ & $12(57.1)$ & $13(44.8)$ & $24(52.2)$ & \\
\hline Lower thoracic & 177 (37.6) & $4(19.0)$ & $12(41.4)$ & $20(43.5)$ & \\
\hline Neoadjuvant therapy $(\%)$ & & & & & .305 \\
\hline Yes & $194(41.2)$ & $8(38.1)$ & $7(24.1)$ & $19(41.3)$ & \\
\hline No & $277(58.8)$ & $13(61.9)$ & $22(75.9)$ & $27(58.7)$ & \\
\hline Surgery $(\%)$ & & & & & .337 \\
\hline Ivor Lewis & $389(82.6)$ & $14(66.7)$ & $23(79.3)$ & $38(82.6)$ & \\
\hline Mckeown & $82(17.4)$ & $7(33.3)$ & $6(20.7)$ & $8(17.4)$ & \\
\hline No. of dissected lymph nodes, mean (range) & $41.2(6-111)$ & $45.1(19-111)$ & $42.9(11-101)$ & $46.4(11-87)$ & .520 \\
\hline No. of positive lymph nodes, mean (range) & $0.87(0-27)$ & $2.43(0-18)$ & $2.00(0-22)$ & $1.93(0-8)$ & .569 \\
\hline \multicolumn{6}{|l|}{ Site of locoregional recurrence } \\
\hline Anastomotic site & & - & 11 & 3 & \\
\hline Mediastinal lymph node & & - & 16 & 4 & \\
\hline Abdominal lymph node & & - & 2 & - & \\
\hline Cervical lymph node & & 21 & - & 4 & \\
\hline \multicolumn{6}{|l|}{ Site of distant recurrence } \\
\hline Lung & & - & - & 28 & \\
\hline Liver & & - & - & 12 & \\
\hline Bone & & - & - & 9 & \\
\hline Pleura & & - & - & 3 & \\
\hline Skin and soft tissue & & - & - & 4 & \\
\hline Peritoneum & & - & - & 4 & \\
\hline Brain & & - & - & 1 & \\
\hline Kidney & & - & - & 1 & \\
\hline
\end{tabular}

Group A, Patients with recurrence in isolated cervical lymph nodes; Group B, patients with recurrence in a locoregional area and without cervical lymph node recurrence; Group $\mathrm{C}$, patients with distant recurrence and with or without locoregional recurrence; $S D$, standard deviation.

described in Tables 1 and 2. Clinical characteristics of patients who received neoadjuvant therapy and who underwent surgery alone are shown in Table 3 . The median survival time for all patients was 93 months $(95 \%$ confidence interval [CI], 70.3-115.6).

Ninety-six of the 471 patients in the study population had recurrent disease after surgery during the follow-up period. Fifty patients had locoregional recurrence, 35 had distant recurrence, and 11 had combined recurrence. Twenty-one recurrences were localized only in the cervical lymph node (group A), 29 recurrences occurred in a locoregional site without cervical lymph node recurrence (group B), and 46 recurrences developed in a distant site with or without locoregional recurrence (group C).

The median times to recurrence after surgery in groups A, $\mathrm{B}$, and $\mathrm{C}$ were 20 months (95\% CI, 17.8-22.2 months), 16 months (95\% CI, 12.9-19.1 months), and 12 months (95\% CI, 9.8-14.2 months), respectively ( $P=.634, \log -$ rank). Seventy-two of 96 patients with recurrence had recurrence within 2 years. Two-, 5-, and 10-year rates of isolated cervical lymph node recurrence were $4.1 \%, 5.6 \%$, and $7.3 \%$, respectively. The median survival times after the recurrence were 13 months (95\% CI, 5.1-21.0 months) in group A, 7 months (95\% CI, 3.6-10.4 months) in group B, and 5 months (95\% CI, 4.5-9.5 months) in group C. There was statistical difference between groups $\mathrm{A}$ and $\mathrm{C}(P=.030)$ (Figure 1).

Risk factors influencing the recurrence of cervical lymph nodes are analyzed in Table 4. Independent risk factors associated with recurrence-free survival of group $\mathrm{A}$ in our study patients, and as assessed by univariate and multivariate analysis, were that the tumor was located in the upper thoracic esophagus $(P=.019)$ and that lymph node metastasis was involved in the recurrent laryngeal lymph node seen at the time of the initial operation $(P=.008)$.

Twelve $(57 \%)$ of 21 patients (group A) had isolated cervical lymph node recurrences in the left side of the neck. The supraclavicular lymph nodes were the most common site of recurrent cervical lymph node disease (16 [76.2\%] of 21 patients). Single cervical node metastasis developed in 7 patients and multiple cervical node metastases in 14. 
TABLE 2. Clinical and pathologic data of our study population

\begin{tabular}{|c|c|c|c|c|c|}
\hline Variable & All patients $(n=471)$ & Group A $(n=21)$ & Group B $(\mathbf{n}=29)$ & Group C $(n=46)$ & $P$ value \\
\hline Clinical T stage $(\%)^{*}$ & & & & & .309 \\
\hline $\mathrm{Tx}$ & $23(4.9)$ & $1(4.8)$ & $3(10.3)$ & $4(8.7)$ & \\
\hline Tis & $7(1.5)$ & $0(0)$ & $1(3.4)$ & $0(0)$ & \\
\hline $\mathrm{T} 1$ & $228(48.4)$ & $10(47.6)$ & $7(24.1)$ & $12(26.1)$ & \\
\hline $\mathrm{T} 2$ & 93 (19.7) & $3(14.3)$ & $11(37.9)$ & $9(19.6)$ & \\
\hline $\mathrm{T} 3$ & $113(24.0)$ & $7(33.3)$ & $7(24.1)$ & $19(41.3)$ & \\
\hline $\mathrm{T} 4$ & $7(1.5)$ & $0(0)$ & $0(0)$ & $2(4.3)$ & \\
\hline Clinical N stage $(\%)^{*}$ & & & & & .150 \\
\hline N0 & $301(63.9)$ & $16(76.2)$ & $19(65.5)$ & $24(52.2)$ & \\
\hline N1 & $170(36.1)$ & $5(23.8)$ & $10(34.5)$ & $22(47.8)$ & \\
\hline Clinical M stage $(\%)^{*}$ & & & & & .194 \\
\hline M0 & $456(96.8)$ & $21(100)$ & $28(96.6)$ & $43(93.5)$ & \\
\hline M1a & $5(1.1)$ & $0(0)$ & $0(0)$ & $0(0)$ & \\
\hline M1b & $6(1.3)$ & $0(0)$ & $1(3.4)$ & $0(0)$ & \\
\hline $\mathrm{Mx}$ & $4(0.8)$ & $0(0)$ & $0(0)$ & $3(6.5)$ & \\
\hline Pathologic $\mathrm{T}$ stage $(\%) \dagger$ & & & & & .209 \\
\hline T0 & $118(25.1)$ & $1(4.8)$ & $4(13.8)$ & $8(17.4)$ & \\
\hline Tis & $17(3.6)$ & $0(0)$ & $0(0)$ & $0(0)$ & \\
\hline $\mathrm{T} 1$ & $212(45.0)$ & $14(66.7)$ & $11(37.9)$ & $12(26.1)$ & \\
\hline $\mathrm{T} 2$ & 55 (11.7) & $4(19.0)$ & $5(17.2)$ & $4(8.7)$ & \\
\hline $\mathrm{T} 3$ & $66(14.0)$ & $2(9.5)$ & $8(27.6)$ & $20(43.5)$ & \\
\hline $\mathrm{T} 4 \mathrm{a}$ & $3(0.6)$ & $0(0)$ & $1(3.4)$ & $2(4.3)$ & \\
\hline Pathologic N stage $(\%) \dagger$ & & & & & .759 \\
\hline No & $330(70.1)$ & $10(47.6)$ & $17(58.6)$ & $20(43.5)$ & \\
\hline N1 & $93(19.7)$ & $6(28.6)$ & $5(17.2)$ & $12(26.1)$ & \\
\hline $\mathrm{N} 2$ & $36(7.6)$ & $2(9.5)$ & $5(17.2)$ & $11(23.9)$ & \\
\hline N3 & $12(2.5)$ & $3(14.3)$ & $2(6.9)$ & $3(6.5)$ & \\
\hline Pathologic M stage $(\%) \dagger$ & & & & & .577 \\
\hline M0 & $468(99.4)$ & $21(100)$ & $29(100)$ & $45(97.8)$ & \\
\hline M1 & $3(0.6)$ & $0(0)$ & $0(0)$ & $1(2.2)$ & \\
\hline Histologic grade $(\%)$ & & & & & .385 \\
\hline 0 & $135(28.7)$ & $1(4.8)$ & $4(13.8)$ & $8(17.4)$ & \\
\hline Gx & $26(5.5)$ & $3(14.3)$ & $0(0)$ & $3(6.5)$ & \\
\hline G1 & $45(9.6)$ & $3(14.3)$ & $5(17.2)$ & $3(6.5)$ & \\
\hline G2 & $229(48.6)$ & $11(52.4)$ & $18(62.1)$ & $27(58.7)$ & \\
\hline G3 & $36(7.6)$ & $3(14.3)$ & $2(6.9)$ & $5(10.9)$ & \\
\hline Metastatic lymph node & & & & & $<.001$ \\
\hline None & $330(70.1)$ & $10(47.6)$ & $17(58.6)$ & $20(43.5)$ & \\
\hline Positive lymph node without RLN & $114(24.2)$ & $3(14.3)$ & $9(31.0)$ & $25(54.3)$ & \\
\hline Positive lymph node with RLN & $27(5.7)$ & $8(38.1)$ & $3(10.3)$ & $1(2.2)$ & \\
\hline
\end{tabular}

Group A, Patients with recurrence in isolated cervical lymph nodes; Group B, patients with recurrence in a locoregional area and without cervical lymph node recurrence; Group $C$, patients with distant recurrence and with or without locoregional recurrence; $R L N$, recurrent laryngeal lymph node. *Clinical stage based on sixth American Joint Committee on Cancer TNM stage. ${ }^{12} \nmid$ Pathologic stage based on seventh American Joint Committee on Cancer TNM stage. ${ }^{13}$

Of 21 patients who had isolated cervical lymph node recurrence (group A), $2(9.5 \%)$ refused further treatment, 6 $(28.6 \%)$ received chemotherapy only, $1(4.8 \%)$ received radiotherapy only, $9(42.9 \%)$ received concurrent chemoradiation therapy, and $3(14.3 \%)$ underwent surgical neck dissection.

Fifteen of the 21 patients died during the follow-up period. There were 2 deaths in patients without further treatment ( 0 and 6 months after recurrence), 4 in those with chemotherapy (1, 3, 6, and 16 months), 7 in those with concurrent chemoradiation therapy $(9,10,12,13,18,21$, and 28 months), and 2 in those with surgical neck dissection (4 and 35 months).

Six of the 21 patients were alive during the follow-up period, 2 patients with chemotherapy (at 0 and 86 months from recurrence to last follow-up), 1 with radiotherapy (56 months), 2 with concurrent chemoradiation therapy (5 and 7 months), and 1 with surgical neck dissection (33 months).

\section{DISCUSSION}

Many different therapeutic options have been attempted to reduce the rate of recurrent disease and to increase the 
TABLE 3. Clinical characteristics of patients who underwent surgery alone $(n=277)$ and neoadjuvant therapy followed by surgery $(n=194)$

\begin{tabular}{lccc}
\hline \multicolumn{1}{c}{ Variables } & $\begin{array}{c}\text { Surgery alone } \\
(\mathbf{n}=\mathbf{2 7 7})\end{array}$ & $\begin{array}{c}\text { Neoadjuvant } \\
\text { therapy } \\
(\mathbf{n = 1 9 4 )}\end{array}$ & $\begin{array}{c}\boldsymbol{P} \\
\text { value }\end{array}$ \\
\hline Clinical T stage (\%)* & & & $<.001 \ddagger$ \\
cTx, cTis, cT1 & $219(79.1)$ & $39(20.1)$ & \\
cT2-4 & $58(20.9)$ & $155(79.9)$ & \\
Clinical N stage (\%)* & & & $<.001 \ddagger$ \\
cN0 & $241(87.0)$ & $60(30.9)$ & \\
cN1 & $36(13.0)$ & $134(69.1)$ & \\
Pathologic T stage (\%) $\dagger$ & & & .293 \\
pT0, pTis, pT1 & $201(72.6)$ & $146(75.3)$ & \\
pT2-4 & $76(27.4)$ & $48(24.7)$ & \\
Pathologic N stage (\%) $\dagger$ & & & .217 \\
pN0 & $189(68.2)$ & $141(72.7)$ & \\
pN1-3 & $88(31.8)$ & $53(27.3)$ & \\
Recurrence at any site (\%) & & & .204 \\
Yes & $62(22.4)$ & $34(17.5)$ & \\
No & $215(77.6)$ & $160(82.5)$ & \\
Recurrence-free survival (\%) & & & .914 \\
2-y & 82.5 & 83.7 & \\
5-y & 75.7 & 79.2 & \\
Overall survival (\%) & & & $<.001 \ddagger$ \\
2-y & 81.7 & 66.7 & \\
5-y & 63.7 & 50.2 & \\
\hline
\end{tabular}

*Clinical stage based on sixth American Joint Committee on Cancer TNM stage. ${ }^{12}$ $\dagger$ Pathologic stage based on seventh American Joint Committee on Cancer TNM stage. ${ }^{13} \ddagger P$ value $<.05$

long-term survival for patients with esophageal cancer worldwide.

Radical esophagectomy with 3-field lymph node dissection (cervical, mediastinal, and abdominal lymph nodes) has been performed by some surgeons, especially Japanese groups. ${ }^{8,9}$ Several studies also suggested that extended lymphadenectomy containing a cervical lymph node dissection may prevent recurrent disease and improve the long-term outcomes. ${ }^{17,18}$ However, other authors have reported that extended nodal dissection did not contribute to reduced recurrence rates or to increased long-term survival outcomes. ${ }^{4,5,10,11,19-21}$ We found that the 2-, 5-, and 10 -year rates of isolated cervical lymph node recurrence were $4.1 \%, 5.6 \%$, and $7.3 \%$, respectively, by using the Kaplan-Meier estimate in this study.

Yano and colleagues ${ }^{6}$ suggested that patients with cervical lymph node recurrence still have the chance of cure, although the prognosis is poor. Motoyama and associates ${ }^{7}$ reported that the survival after recurrence in patients with cervical recurrence was significantly longer than in patients with other recurrences. At the present study, the median time to recurrence after surgery was longer in group A than in groups B and C, although there was no statistical difference. Survival after recurrence in group A was significantly longer than that of group $\mathrm{C}$, although there was no statistical difference between groups A and B.

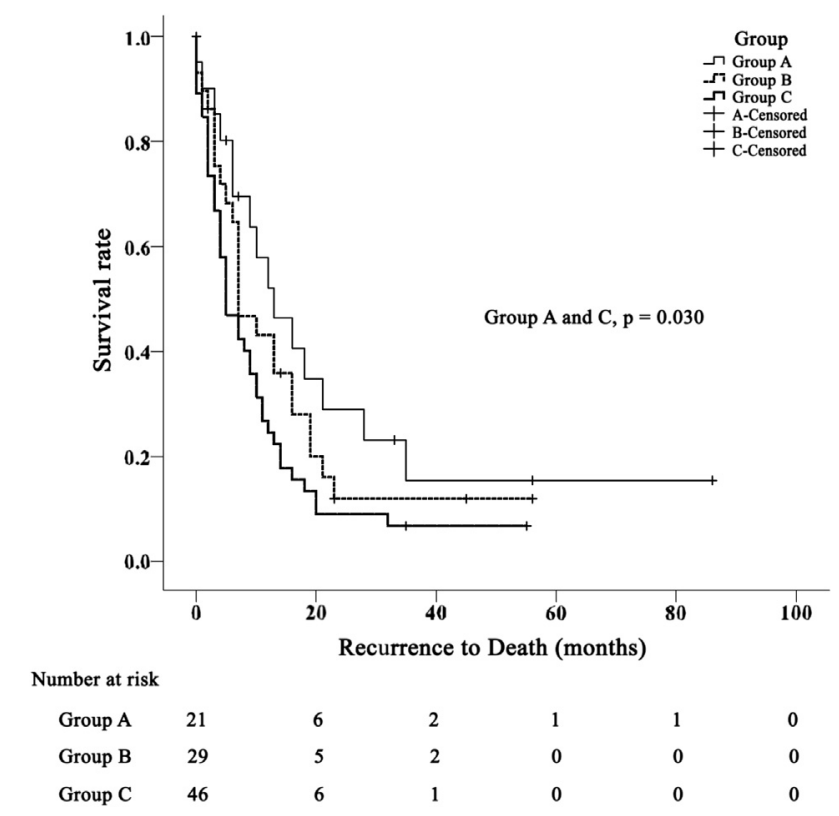

FIGURE 1. Overall survival curve from the date of the recurrence to the date of death or last follow-up in groups A, B and C by using a KaplanMeier estimate.

As shown in the present study, upper thoracic esophageal carcinoma and metastasis of recurrence in laryngeal lymph nodes at the time of surgery were independent risk factors for recurrence-free survival of patients with cervical lymph nodal recurrence (group A). It is often suggested that the prognosis of upper thoracic esophageal cancer is poorer than that of middle or lower thoracic esophageal cancer. ${ }^{22} \mathrm{Ta}-$ bira and colleagues ${ }^{23}$ suggested that recurrent laryngeal node involvement was a significant factor associated with cervical node metastasis at the time of surgery, although they did not

TABLE 4. Univariate and multivariate analysis for recurrence-free survival in patients with cervival lymph node recurrence (group A) by using the Kaplan-Meier method and Cox regression model

\begin{tabular}{|c|c|c|c|c|}
\hline \multirow[b]{3}{*}{ Variables } & \multicolumn{4}{|c|}{ Analysis } \\
\hline & \multirow{2}{*}{$\begin{array}{c}\text { Univariate } \\
P \text { value }\end{array}$} & \multicolumn{3}{|c|}{ Multivariate } \\
\hline & & HR & $95 \% \mathrm{CI}$ & $P$ value \\
\hline Age & .196 & & & \\
\hline Gender & .593 & & & \\
\hline Neoadjuvant therapy & .793 & & & \\
\hline Clinical T stage $\dagger$ & .697 & & & \\
\hline Clinical N stage $\dagger$ & .490 & & & \\
\hline Tumor location & $.006^{*}$ & 2.422 & $1.159-5.061$ & $.019 *$ \\
\hline Pathologic T stage $\ddagger$ & .248 & & & \\
\hline Pathologic N stage $\ddagger$ & $<.001 *$ & 1.169 & $0.570-2.397$ & .670 \\
\hline Histologic grade & .295 & & & \\
\hline RLN metastasis & $<.001 *$ & 2.839 & $1.311-6.148$ & $.008 *$ \\
\hline
\end{tabular}


report how cervical lymph node recurrence occurred after surgery in their study group. Shim, Kim, and $\mathrm{Kim}^{21}$ reported that recurrent laryngeal lymph node metastasis was $35 \%$ in their 2-field group and that the rates of recurrent laryngeal lymph node metastasis and cervical lymph node metastasis were $37 \%$ and $19 \%$, respectively, in their 3-field group. However, there was no significant difference in cervical lymph node recurrence after surgery in either group.

In this study, neoadjuvant therapy was administered in nearly half the patients comprising the study population. The overall survival of patients with surgery alone was statistically better than that of patients with neoadjuvant therapy, but there were no statistical differences in the recurrence rate and recurrence-free survival after surgery between the 2 groups. However, these results do not mean that the treatment value of neoadjuvant therapy is worse than the value of surgery alone, because patients with advanced clinical stage were more likely to be in the neoadjuvant group.

Dresner and Griffin ${ }^{4}$ indicated that metastasis of cervical lymph nodes at the time of surgery may not be associated with clinical recurrence and that it may already be a manifestation of systemic disease. Nakagawa and colleagues ${ }^{24}$ suggested that these patients may already have micrometastatic disease beyond the area of extended lymphadenectomy at the time surgery. Meguid and associates ${ }^{25}$ insisted that neoadjuvant treatment is critical in preventing recurrent disease and that it may also eliminate distant disease or micrometastasis outside of the local surgical or radiation field. For these reasons, they suggested that surgery alone containing nodal clearance, regardless of the extent of nodal dissection, is considered only as a local control. They also emphasized that recurrence and long-term survival are probably related not only by the extent of surgical procedure, but also by neoadjuvant or adjuvant modalities and various biologic and histologic tumor-related factors.

\section{Study Limitations}

The present study has several limitations. First, this study was a retrospective analysis. Second, a comparison between 2-field and 3-field lymph node dissection could not be performed. Third, the statistical power for the survival and risk factor analyses may be weak inasmuch as the number of subgroups was relatively small. Fourth, cancer recurrence rate must be reported in a time-related manner, inasmuch as a recurrence is considered to be a time-related diagnosis. Unfortunately, we were not able to compare our results with other reports, because few reports have described the cervical lymph node recurrence rate in a time-related manner. As the efficacy of radical extended nodal dissection remains controversial, it is important to directly compare the outcomes of 2-field and 3-field lymph node dissection, and it is crucial that prospective, randomized, controlled trials be conducted to determine the most effective modalities for improving the therapeutic outcomes for patients with esophageal cancer.

\section{CONCLUSIONS}

We found that the 2-, 5-, and 10-year rates of isolated cervical lymph node recurrence were $4.1 \%, 5.6 \%$, and $7.3 \%$, respectively, in patients who had undergone 2-field lymph node dissection. The survival of patients with isolated cervical lymph node recurrence was relatively better than that of patients with recurrence at other sites. This shows that 2-field lymph node dissection can be performed with an acceptable rate of cervical recurrence. Independent risk factors for recurrence-free survival of patients with cervical recurrence were a tumor located in the upper thoracic esophagus and metastasis of a recurrent laryngeal lymph node that already existed at the time of surgery.

\section{References}

1. Earlam R, Cunha-Melo JR. Oesophageal squamous cell carcinoma: I. A critical review of surgery. Br J Surg. 1980;67:381-90.

2. Swisher SG, Deford L, Merriman KW, Walsh GL, Smythe R, Vaporicyan A, et al. Effect of operative volume on morbidity, mortality, and hospital use after esophagectomy for cancer. J Thorac Cardiovasc Surg. 2000;119:1126-32.

3. Nakamura T, Ota M, Narumiya K, Sato T, Ohki T, Yamamoto M, et al. Multimodal treatment for lymph node recurrence of esophageal carcinoma after curative resection. Ann Surg Oncol. 2008;15:2451-7.

4. Dresner SM, Griffin SM. Pattern of recurrence following radical oesophagectomy with two-field lymphadenectomy. Br J Surg. 2000;87:1426-33.

5. Mariette C, Balon JM, Piessen G, Fabre S, Van Seuningen I, Triboulet JP. Pattern of recurrence following complete resection of esophageal carcinoma and factors predictive of recurrent disease. Cancer. 2003;97:1616-23.

6. Yano M, Takachi K, Doki Y, Miyashiro I, Kishi K, Noura S, et al. Prognosis of patients who develop cervical lymph node recurrence following curative resection for thoracic esophageal cancer. Dis Esophagus. 2006;19:73-7.

7. Motoyama S, Kitamura M, Saito R, Maruyama K, Okuyama M, Ogawa J. Outcome and treatment strategy for mid- and lower-thoracic esophageal cancer recurring locally in the lymph nodes of the neck. World J Surg. 2006;30:191-8

8. Kato H, Watanabe H, Tachimori Y, Iizuka T. Evaluation of neck lymph node dissection for thoracic esophageal carcinoma. Ann Thorac Surg. 1991;51:931-5.

9. Nishihira T, Hirayama K, Mori S. A prospective randomized trial of extended cervical and superior mediastinal lymphadenectomy for carcinoma of the thoracic esophagus. Am J Surg. 1998;175:47-51.

10. Law S, Wong J. Lymph node dissection in surgical treatment of esophageal neoplasms. Surg Oncol Clin N Am. 2007;16:115-31.

11. Orringer MB, Marshall B, Chang AC, Lee J, Pickens A, Lau CL. Two thousand transhiatal esophagectomies: changing trends, lessons learned. Ann Surg. 2007; 246:363-72.

12. Greene FL, Compton CC, Fritz AG, Shah JP, Winchester DP, Compton CC, et al. AJCC Cancer Staging Atlas. 6th ed. New York (NY): Springer; 2006.

13. Edge SB, ed. AJCC Cancer Staging Manual. 7th ed. New York (NY): Springer; 2010.

14. Lee JL, Kim SB, Jung HY, Park SI, Kim DK, Kim JH, et al. Efficacy of neoadjuvant chemoradiotherapy in resectable esophageal squamous cell carcinomaa single institutional study. Acta Oncol. 2003;42:207-17.

15. Park JW, Kim JH, Choi EK, Lee SW, Yoon SM, Song SY, et al. Prognosis of esophageal cancer patients with pathologic complete response after preoperative concurrent chemoradiotherapy. Int J Radiat Oncol Biol Phys. 2011;81:691-7.

16. Koo DH, Park SI, Kim YH, Kim JH, Jung HY, Lee GH, et al. Phase II study of use of a single cycle of induction chemotherapy and concurrent chemoradiotherapy containing capecitabine/cisplatin followed by surgery for patients with resectable esophageal squamous cell carcinoma: long-term follow-up data. Cancer Chemother Pharmacol. 2012;69:655-63.

17. Stiles BM, Mirza F, Port JL, Lee PC, Paul S, Christos P, et al. Predictors of cervical and recurrent laryngeal lymph node metastases from esophageal cancer. Ann Thorac Surg. 2010;90:1805-11.

18. Jang HJ, Lee HS, Kim MS, Lee JM, Zo JI. Patterns of lymph node metastasis and survival for upper esophageal squamous cell carcinoma. Ann Thorac Surg. 2011; 92:1091-7. 
19. Junginger T, Gockel I, Heckhoff S. A comparison of transhiatal and transthoracic resections on the prognosis in patients with squamous cell carcinoma of the esophagus. Eur J Surg Oncol. 2006;32:749-55.

20. Kunisaki C, Makino H, Takagawa R, Yamamoto N, Nagano Y, Fujii S, et al. Surgical outcomes in esophageal cancer patients with tumor recurrence after curative esophagectomy. J Gastrointest Surg. 2008;12:802-10.

21. Shim YM, Kim HK, Kim K. Comparison of survival and recurrence pattern between two-field and three-field lymph node dissections for upper thoracic esophageal squamous cell carcinoma. J Thorac Oncol. 2010;5:707-12.

22. Shimada H, Matsubara H, Okazumi S, Isono K, Ochiai T. Improved surgical results in thoracic esophageal squamous cell carcinoma: a 40-year analysis of 792 patients. J Gastrointest Surg. 2008;12:518-26.
23. Tabira Y, Yasunaga M, Tanaka M, Nakano K, Sakaguchi T, Nagamoto N, et al Recurrent nerve nodal involvement is associated with cervical nodal metastasis in thoracic esophageal carcinoma. J Am Coll Surg. 2000;191:232-7.

24. Nakagawa S, Kanda T, Kosugi S, Ohashi M, Suzuki T, Hatakeyama K. Recurrence pattern of squamous cell carcinoma of the thoracic esophagus after extended radical esophagectomy with three-field lymphadenectomy. J Am Coll Surg. 2004;198:205-11.

25. Meguid RA, Hooker CM, Taylor JT, Kleinberg LR, Cattaneo SM 2nd Sussman MS, et al. Recurrence after neoadjuvant chemoradiation and surgery for esophageal cancer: does the pattern of recurrence differ for patients with complete response and those with partial or no response? J Thorac Cardiovasc Surg. 2009;138:1309-17 